\title{
Pistas para um estudo do sensível
}

\author{
ARAÚJO, Eline Gomes de ${ }^{1}$ \\ $P A Z$, Carolina Albuquerque $\mathrm{da}^{2}$ \\ MELO, Lorena Albuquerque de ${ }^{3}$
}

\section{RESUMO}

Este artigo tem por inspiração escrever sobre os caminhos trilhados pelo laboratório de sensibilidades do curso de medicina, do Núcleo de Ciências da Vida (NCV) da Universidade Federal de Pernambuco (UFPE) - campus agreste em Caruaru-PE, e sugerir algumas pistas para a formação sensível no campo da saúde, a partir da experiência vivida pelos docentes do laboratório e do curso. Também apresenta de forma breve as discussões que ocorreram durante o primeiro ENSENSI - Encontro Nacional Sobre o Sensível nas Graduações em Saúde, com o tema "a (Re)Existência do Sensível", organizado por este curso, em 2018. Tem por objetivo problematizar os caminhos, as estratégias políticopedagógicas do laboratório e o desenho pedagógico que ganhou forma. Discute a possível transformação do paradigma da formação em saúde e especialmente a formação médica.

Educação médica. Sensibilidades. Laboratório de sensibilidades. Arte e medicina.

\section{Trails to a study of the sensitive}

\section{ABSTRACT}

This article is inspired by writing about the paths taken by the laboratory of sensitivities of the medical course of the Life Sciences Nucleus (NCV) of the Federal University of Pernambuco (UFPE) - in Caruaru-PE, and to suggest some clues for sensitive education in the health field in higher education, based on the experience lived by the laboratory and course teachers. It also briefly presents the discussions that took place during the first ENSENSI - National Meeting on the Sensitive in Health Graduations, with the theme "the $(\mathrm{Re})$ Existence of the Sensitive", organized by this course in 2018. It aims to problematize the paths, the political-pedagogical strategies of the laboratory and the pedagogical design that took shape. It discusses the possible transformation of the health education paradigm and especially medical education.

\footnotetext{
1 Doutoranda em Bioética (DINTER UnB/UFPE),Professora do Curso de Medicina (UFPE); Mestre em Dança (UFBA). E-mail: elinegomes21@gmail.com. Lattes: http://lattes.cnpq.br/2007171709842370. ORCID: https://orcid.org/0000-0002-3013-7425.

2 Doutoranda em Bioética (DINTER UnB/UFPE), mestre em Promoção da Saúde (Canadá)Professora do Curso de Medicina (UFPE); E-mail: carolpaz07@gmail.com. Lattes: http://lattes.cnpq.br/8490845240070841. ORCID: https://orcid.org/0000-0003-1997-0720. ${ }^{3}$ Fisioterapeuta da Prefeitura da Cidade do Recife. Email: Iorenalbuquerque@gmail.com. Lattes: http://lattes.cnpq.br/1661663846343148. ORCID: https://orcid.org/0000-0002-57438148.
}

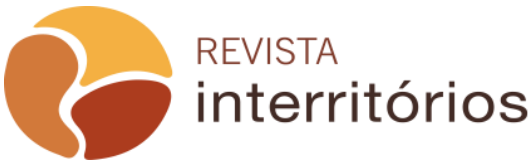


Medical education. Sensitivities. Sensitivity laboratory. Art and Medicine.

\section{Huellas Para un Estudio de lo Sensible}

\section{RESUMEN}

Este artículo está inspirado para escribir sobre los caminos tomados por el laboratorio de sensibilidad del curso de medicina, en el Centro de Ciencias de la Vida (NCV) de la Universidad Federal de Pernambuco (UFPE), campus en agreste en Caruaru-PE, y para sugerir algunas huellas para la formación sensible en el campo de la salud, basada en la experiencia vivida por los maestros del laboratorio y del curso. También presenta brevemente las discusiones que tuvieron lugar durante la primera ENSENSI - Encuentro Nacional sobre el Sensible en las Graduaciones en Salud, con el tema "la $(R e)$ existencia de lo sensible", organizado por este curso, en 2018. Su objetivo es problematizar los caminos, las estrategias político-pedagógicas del laboratorio y el diseño pedagógico que tomó forma. Discute la posible transformación del paradigma de formación en salud y especialmente la capacitación médica.

Educación Médica. Sensibilidades Laboratorio de sensibilidad. Arte y medicina.

\section{Indizi su uno Studio di Sensibilità}

\section{SINTESE}

Questo articolo si ispira scrivendo sui percorsi intrapresi dal laboratorio di sensibilità del corso medico del Life Sciences Nucleus (NCV) dell'Università Federale del Pernambuco (UFPE) - nel campus di Caruaru-PE, e suggerendo alcuni indizi per formazione sensibile in campo sanitario, basata sull'esperienza vissuta dal laboratorio e dagli insegnanti del corso. Presenta inoltre brevemente le discussioni svoltesi durante il primo ENSENSI - Incontro nazionale sulle graduatorie sensibili in salute, con il tema "La (ri) esistenza del sensibile", organizzato da questo corso nel 2018. Ha lo scopo di problematizzare il percorsi, le strategie politico-pedagogiche del laboratorio e il design pedagogico che ha preso forma. Discute la possibile trasformazione del paradigma dell'educazione sanitaria e in particolare dell'educazione medica.

Educazione medica. Sensibilità. Laboratorio di sensibilità. Arte e medicina.

\section{INTRODUÇÃO}

Uma trilha não é propriamente um caminho totalmente conhecido, mas um caminho para o qual o caminhante deve estar apto aos imprevistos, e relaciona-se com a sensação de desafio. Nesse trilhar compartilhado de sonhos, 
fez-se o laboratório de sensibilidades, habilidades e expressão (LABSHEX), cujos fundadores descrevem um pouco essa trajetória inicial no artigo "Saber é sentir, sentir é saber: o ponto de partida do LabSensi" a ser publicado na mesma edição desta revista, das autoras Maria Verônica Araújo de Santa Cruz Oliveira e Rafaela Alves Pacheco.

Este artigo busca resgatar trilhas que foram abertas no LabSensi após o primeiro ano de sua fundação. A primeira trilha se abre quando tecemos uma reflexão entre bases teóricas e metodológicas que foram se somando ao longo desta caminhada com as potencialidades deste espaço pedagógico em contraponto às dificuldades e resistências que encontramos. Isto porque ao serem escutadas, nos levaram a necessidade da reconfiguração do LabSensi. A segunda trilha que traremos neste artigo nos liga ao contexto nacional, ampliando nosso diálogo com outros laboratórios e experiências do ensino do sensível a partir da realização do $1^{\circ}$ ENSENSI - Encontro Nacional sobre 0 Sensível nas Graduações em Saúde.

\author{
Cena de Dança 1 \\ Sonhe \\ Cena de Dança 2 \\ Sonhe junto. \\ YOKO ONO, 2014
}

Uma pista nesse caminho pode ser o olhar sobre o encontro dos professores fundadores e Maria Verônica A.S.C. Oliveira, psicóloga do Curso e suas trajetórias de vida, na opção por construir juntos o curso de medicina de Caruaru. Uma parte destes atores com percursos em movimentos de militância social, como o movimento estudantil, com diversas discussões e potentes contribuições na transformação da educação médica, e outra parte deles e delas também em movimentos como o da educação popular em saúde, eles e elas contribuíram, de certa forma, para as perspectivas acumuladas na proposta do Curso.

Não tendo a pretensão de trazer um histórico detalhado de cada um nem um relatório mais complexo sobre a crise na medicina moderna e as transformações da educação médica, vamos apontar os principais pilares ou eixos de trabalho do laboratório e suas configurações práticas, assim como alguns processos de mudança.

\title{
Três pilares para o laboratório
}

Começa aí, portanto, nesse corpo-a-corpo" primeiro mantido com o mundo que nos rodeia, a aventura do saber e do conhecer humanos. Sem dúvida, há um saber sensível, inelutável, 
primitivo, fundador de todos os demais conhecimentos, por mais abstratos que estes sejam; um saber direto, corporal, anterior às representações simbólicas que permitem os nossos processos de raciocínio e reflexão. E será para essa sabedoria primordial que deveremos voltar a atenção se quisermos refletir acerca das bases sobre as quais repousam todo e qualquer processo educacional, por mais especializado que ele se mostre. [...] (DUARTE JUNIOR, 2001, p.12)

Partindo da proposta de um saber sensível ${ }^{4}$, trazendo luz às críticas da hegemonia das racionalidades biomédicas nos cursos de medicina, o laboratório foi engendrado em três estruturas fundantes principais: a ideia do uso de ferramentas sensíveis, incluindo arte, como proto-habilidades médicas; a proposta de um espaço para reflexão e Cuidado de $\mathrm{Si}$, na perspectiva de Foucault (1985); e de forma ainda diluída no contexto inicial - diria até inespecífica - o eixo das artes como campo de experiências sensíveis e formadoras per se.

O termo proto-habilidades médicas não é facilmente encontrado nos dicionários e parece ainda ter poucas publicações relacionadas quando buscamos por esse descritor em bases de publicações científicas associadas à educação médica. 'Proto' do grego prôtos, significa primeiro, o que está à frente (HOUAISS, 2001). Aqui está sendo usado no sentido de algo anterior, primitivo, antes do desenvolvimento das habilidades semiológicas em si. Há, contudo, ferramentas para inferir que algumas práticas têm sido usadas na educação médica no sentido de "sensibilizar" os estudantes para determinados temas e habilidades, especialmente as artes visuais para treinamento da habilidade de observar como ferramenta diagnóstica (MUKUNDA; COLS, 2019). Nesta relação, a construção dessa proposta parece unidirecional, no sentido de profissionais da saúde que buscam a arte - seja de forma amadora ou profissional - para uma aplicabilidade utilitária na prática pedagógica. Ainda é muito incipiente a participação de artistas no processo de ensino-aprendizagem em cursos de nível superior na área de saúde. Neste sentido, o laboratório de sensibilidades de Caruaru tem inovado, com uma proposta de formação de um núcleo de professores de artes que tratem de forma dialética a produção do conhecimento através e com a arte, como discorreremos adiante. Heloísa Germany, que foi professora do laboratório de sensibilidades no curso de medicina no período de 2016 a 2017, apresentou um pouco deste olhar do artista e seu papel na formação de futuros profissionais médicos/as em evento nacional de educação médica, recebendo prêmio de menção honrosa do congresso (GERMANY, 2017, p.665).

\footnotetext{
${ }^{4}$ Este conceito vem sendo usado por Duarte Júnior (2001), estruturando seu discurso a partir de autores como Merleau Ponty e da Michel Maffesoli.

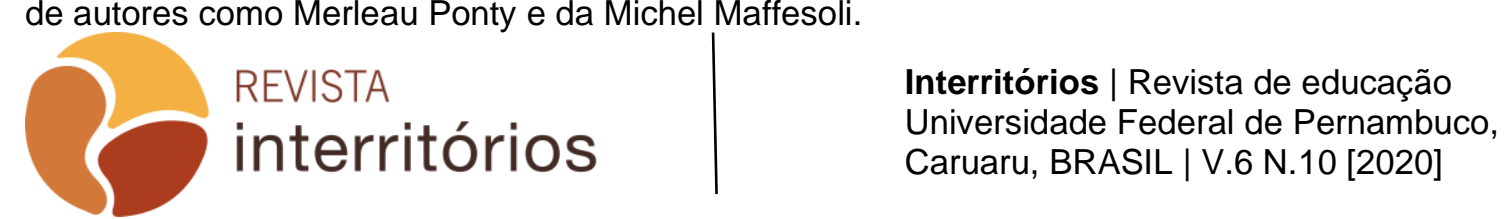


Também a educação popular vem sendo usada especialmente no âmbito da extensão universitária como proposta de aproximação e sensibilização do estudante com a realidade social, deslocando do automatismo habitual do tecnicismo intramuros para uma realidade viva e dinâmica (VASCONCELOS, 2001, OLIVEIRA, 2000). A educação popular tem se tornado uma ferramenta potente de formação, embora seja extracurricular, não obrigatória, fazendo uma espécie de formação complementar por muitos ainda não valorizada ou não atingindo todos os que deveriam ser atingidos. Também a perspectiva do 'trabalho vivo em ato' na saúde (MERHY, 2000, 2009), compreende o ato de cuidar da vida como produto deste trabalho em saúde. Este conceito com foco nas 'tecnologias leves' (relacional) aplicado à formação de profissionais de vários cursos de saúde, traz a experiência real como formadora de habilidades sensíveis para lidar com o contexto clinico e social de forma mais humana. Como explica Merhy:

Qualquer encontro é encontro de uma multidão em produção. E, é nesse plano de imanência que o saber-fazer é de fato fazersaber, isto é, o saber emerge do campo da ação inscrita no encontro e como tal não pode ser a priori, só o sendo imaginariamente. Como tal, o encontro é sempre um lugar de porosidades, de fugas incontroláveis e, por isso, de imprevisibilidade, de incertezas, a tornarem precários todos os arranjos que se posicionam antes do próprio acontecimento. (MERHY, 2013, p.22)

Neste sentido, o encontro com a realidade e a emergência de situações práticas de conflito não são apenas orientadoras para busca de um conhecer, mas produtoras de um saber-fazer inerente à vivência. Na proposta do Curso de Caruaru, esse papel vem sendo atribuído ao módulo PIESC - Prática Interdisciplinar de Ensino, Serviço e Comunidade - no qual, desde o primeiro ano do curso, os alunos estão inseridos nas comunidades e seus territórios com diferentes objetivos pedagógicos a cada ano (UFPE, 2014). A sensibilidade aí transborda os limites do laboratório e constrói suas próprias pontes com o conceito de trabalho vivo em ato (MERHY, 2000). Tem sido desejo de o laboratório de sensibilidades ampliar essas pontes e cruzamentos internos com o PIESC, ainda um projeto em semeadura.

Intentamos proporcionar no laboratório o encontro de cada pessoa consigo mesma e com o outro como humanos, antes de médicos, antes de profissionais, antes de cuidadores, antes do cenário no trabalho ou no campo, tornando-se disponíveis para uma experimentação de si sobre o mundo, e negociando com as informações - de toda qualidade e espécie, e não apenas as verbais - já integradas ao seu constructo de pessoa humana e as novas informações que aí se deslocarem e relocarem, chegarem, ins ou estabilizarem, 
para lidar com o outro. Como pista, o conceito de corpomídia, de Helena Katz e Christine Greiner, contribui para distanciar a metáfora do corpo-máquina, e aproximar de um corpo no qual sua subjetividade está imbricada ao biológico e não separada dele - alimentando essa ideia de negociação e construção continua a partir das experiências vividas (GREINER, 2005; KATZ, 2005).

Os órgãos psicomotores fazem parte do modo de nos tornamos seres no mundo. O processo pelo qual as informações que nos constituem tomam a forma do nosso corpo é longo, e se estrutura na experiência. (KATZ, 2005, p. 56).

Enquanto a percepção se organiza em estados corporais/cognitivos mais ou menos duráveis, os padrões que estabelecem resultados na percepção vão se atualizando no todo, no corpo, constructo do eu (Idem).

Com relação a concepção do eixo de práticas de cuidados de si - o que muitas vezes tem sido relacionado ao simples autocuidado cotidiano - tem-se compreendido que as atividades desenvolvidas no laboratório não podem se tornar incoerentes com sua própria proposta e fechar os olhos para um sistema educacional cruel com os discentes. Isto é, cruel tanto no sentido de carga horária exigida como pelo "espírito" de competitividade com os quais os mesmos já chegam à universidade, corrompidos pelo sistema capital que impõe a todos um melhor resultado para a sobrevivência e o reconhecimento profissional. Assim, o laboratório busca aceitar momentos nos quais percebe a necessidade de repouso, de práticas de relaxamento, e mesmo de diálogos acolhedores em suas aulas. Entretanto, não se compreendendo como espaço terapêutico em si, mas como espaço pedagógico, essa forma de aprender sobre si diz mais sobre formação de si do que sobre uma prática de saúde direta aplicada - como um serviço de assistência prestado aos estudantes. Tangenciando menos uma abordagem terapêutica de saúde psíquica individual - que por vezes está sim indicada e há técnicos no curso e projetos para isso - e mais o que Michael Foucault chamou de "a intensidade das relações consigo", a proposta do laboratório traz este foco, um cuidado de si que é mais um estudo de si e do outro, distanciando da ideia de individualismo que as práticas do cuidado de si podem levantar (FOUCAULT, 1985). A partir do conceito de cuidado de si como prática social, esta fundamentação enriquece e entremeia as relações com os outros eixos estruturantes do laboratório.

No projeto político pedagógico do curso percebemos a imbricação deste com as novas diretrizes curriculares dos cursos de medicina (BRASIL, 2014) e os potenciais de transformação da educação médica aí implicados. Para abrir espaço para esse lugar de disputa num novo modo de formar médicos e médicas, é preciso deslocamentos, desterritorializações, fugir um pouco do padrão habitual de comportamentos. Só o novo é capaz de trazer novas 
perspectivas e tem o potencial de mudar atitudes. Acreditamos que aqui a arte desempenha um papel fundamental nessa formação cidadã, do ser/estar no mundo, para além de uma formação tecnicista. Purismos e idealizações à parte, aqui se faz uma escolha sobre que arte potencializa nossos desejos de mudança. Uma arte de resistência, de um pensamento da diferença, de um olhar nômade (PESCUMA, 2013).

O pensamento da diferença está relacionado a um modo nômade de viver, de sentir por afetos, estabelecendo alianças; [...] Leroi-Gourhan, ao falar da diferença do modo de ver do sedentário e do nômade, diz que o primeiro tem um ponto de vista irradiante, coloca-se no centro e a partir daí olha tudo a sua volta, em círculos concêntricos e hierarquizados. O nômade tem um ponto de vista itinerante, vai construindo a imagem das coisas à medida que se movimenta. (PESCUMA, 2013, p.23)

Dentre essas competências do/a profissional médico/a, está um espectro delas relacionadas a uma formação mais humanista, sensível, e voltada às necessidades da população. Mas como de fato a arte poderia contribuir para esta formação? Diversos caminhos podem ser adotados com linguagens artísticas, dentre eles o da fruição, o que tem acontecido especialmente com obras do audiovisual, com debates subsequentes, forma mais comum de inserção desta linguagem na área de educação. Também mais confortável, no sentido de ocupar um lugar cognitivo central, ao elaborar verbalmente as reflexões sobre determinado filme ou trecho de filme exposto. Todavia, apostamos também nas artes visuais e plásticas como modo de construir, de ver o mundo e de ressignificar questões do humano, de um lugar mais ativo e propositivo do que apenas apreciador. Também o movimento que acontece através de técnicas de improvisação e técnicas somáticas, parte de um lugar mais sensorial, de valorizar outros sentidos na construção da percepção, para viver e estudar o corpo, em si mesmo e no colega ao lado, para chamar isso de dança. É um outro modo de deslocar o cognitivo racional para um outro modo de produzir saber. A partir da perspectiva de Antônio Damásio (2000), Araújo explica outras formas de conhecer

Sendo o ato de conhecer o substrato básico da consciência mesmo antes que qualquer linguagem verbal (DAMÁSIO, 2000), podemos dizer que o corpo consciente (com consciência), está continuamente produzindo esse conhecer. E que tanto o ato de conhecer como o consequente conhecimento produzido são modulados pelas emoções (idem). Se o corpo está produzindo conhecimento a todo momento, assim também o faz quando dança. Mas há especificidades a serem ressaltadas." (ARAÚJO, 2010, p.72) 
Vieira (2006) nos chama a atenção que a arte, por trabalhar as diferentes possibilidades do real é, como um campo de saber, mais ampla que a ciência no sentido de explorar a realidade, sendo também uma forma de conhecimento. Segundo Vieira,

A questão real é que arte é forma de conhecimento e todo conhecimento é função vital, todo conhecimento garante vida e complexidade. Desvalorizar o artístico é matar, em altos níveis de complexidade, nossa Humanidade. Insistimos aqui: a Arte é o tipo de conhecimento que explora as possibilidades do real. Não nos basta acreditar em uma certa realidade, temos que aprender os caminhos complexos para atingi-la, e temos que fazer isso para sobreviver, não só em corpo, mas nos signos que já somos capazes de produzir e extrasomatizar, além das necessidades biológicas. (VIEIRA, 2006, p. 83)

\section{A escuta das resistências para o abrir de novas trilhas}

Ao final do ano de 2015, vínhamos mantendo uma estrutura pedagógica de aulas que combinavam habilidades médicas e sensibilidades, num período de quatro horas seguidas semanais, dividido num modelo com 3 professores que mantinham seu subgrupo de aulas ao longo do semestre. Várias contingências se apresentavam ao curso neste momento como a insuficiência de professores e oposição política de alguns docentes. Deste modo, havia professores que se negavam a assumir responsabilidades pedagógicas e se acomodavam no lugar do silêncio ou mesmo da indisponibilidade de tempo. Ainda vale ressaltar dentre outras camadas de divergências pedagógicas, desconfianças quanto às metodologias ativas de aprendizagem (elementos centrais no curso) e outros boicotes individuais que envolveram, inclusive, discentes - culminando na complexidade de um problema que transitava entre a sensação de insegurança num caminho do novo, que seria entendido como "sensibilidades" e a insuficiência de competências e habilidades atribuídas como essenciais à formação médica. Aqui o caminho novo e inseguro estava sendo atribuído não apenas ao uso das metodologias ativas de ensino-aprendizagem, mas principalmente ao espaço "experimental" das sensibilidades.

Houve um boicote às aulas do laboratório ao final de 2015. Nesta época, ao final do semestre, outros professores novos recém-chegados ao curso se dispuseram a colaborar com suas aulas no laboratório, ainda mesclando habilidades e sensibilidades, porém sofreram com boicote e foram tratados de forma rude por alguns dos estudantes. A forma rude não envolveu violência física, mas um questionamento constante de suas competências e seu lugar de 
fala, de uma forma que gerou desgaste emocional de muitos de nossos professores. Mesmo hoje, após uma reformulação na estrutura pedagógica do laboratório, uma parte dos docentes não assume aulas sem tensionamentos neste espaço.

Algumas críticas dos alunos eram sobre o não saber o que iria acontecer nas aulas, achar que não estavam aprendendo algo, argumentavam que não serão artistas no futuro (no caso de aulas que envolviam linguagens artísticas), que estavam perdendo tempo enquanto poderiam estar estudando conteúdos e aprendendo habilidades. Neste sentido, a bagagem acumulada dos professores e técnicos que cultivavam um ambiente acadêmico que valorizava as diferentes verdades e suas formas de produção, abrindo espaço para a discussão e vivência de outras racionalidades de produção de saúde e mesmo de outros campos de conhecimento, aliados ao contexto macropolítico de acirramento entre posições de esquerda e direita no país - posteriormente culminando com o golpe jurídico-midiático contra a democracia em 2016 - aumentaram os tensionamentos para a rejeição dos estudantes às propostas do laboratório e não apenas, mas ao laboratório em si, materializando o boicote às aulas deste espaço no final de 2015.

Após o boicote, foi realizado uma reunião de planejamento e apresentado uma proposta de reestruturação do laboratório. Em reunião histórica, como quando se compartilham as utopias, docentes e colaboradores do laboratório de sensibilidades problematizaram a situação encontrada e compreenderam que novas estratégias eram necessárias para a sobrevivência pedagógica deste espaço. Pensou-se num cardápio de atividades, que ofertassem experiências em "oficinas" mais curtas, através das diferentes linguagens artísticas, com duração de duas horas cada, e separando os "conteúdos" ou competências relacionadas às habilidades das sensibilidades. Assim ficou clara que a lacuna das aulas de habilidades médicas não dependia - ou não deveria depender apenas de professores do laboratório "das sensibilidades" mas sim do melhor professor capacitado para tal, seja ele generalista ou especialista.

O laboratório de sensibilidades é central numa proposta de construir fissuras nos modos de produzir saúde e de formar profissionais de saúde apenas conectado as racionalidades médicas modernas. Assim, decidiu-se separar as habilidades das sensibilidades, criando um espaço identificável de locus do saber para cada um dos seus componentes do LABSHEX (Laboratório de Sensibilidades, Habilidades e Expressão - nome original do laboratório). Passou a haver então o componente habilidades - incluída aí principalmente a semiologia, as práticas de procedimentos que requerem a habilidade do fazer, e algumas habilidades de comunicação - e um componente sensibilidades, no qual estariam mantidos o foco nos três pilares do laboratório. De certa forma, o LabSensi também trabalha habilidades pois tem como foco inclusive algumas 
(proto)habilidades como perspectivas de olhar, toque e habilidades de comunicação.

Inicialmente, para o terceiro pilar do laboratório, o que diz respeito a arte como central na proposição de experiências formadoras, houve uma proposta de oferta de um repertório de aulas optativas, mas com uma carga horária mínima a ser cumprida. O estudante deveria escolher a "linguagem" artística que mais lhe atraísse ao aprendizado para o tema - e todas as "oficinas" estariam trabalhando a mesma temática, porém de formas diferentes. Mantendo a ênfase em vivências, mas de forma mais distribuída no plano pedagógico, a experiência estética ou sensorial consciente - se assim se pode chamar - ganha o foco na aula do laboratório. A experiência singular proporcionada por processos artísticos ganhando uma camada pedagógica, no sentido que John Dewey (2010) chama de única, que dá o caráter de unidade, quando aquilo que foi vivenciado em suas etapas organiza um desfecho, é possível chamar isso de experiência estética. Segundo Dewey,

[...] Assim, quando aparece o estético, ele contrasta tão nitidamente com a imagem formada sobre a experiência que é impossível combinar suas qualidades especiais com as características da imagem, e o estético recebe um lugar e um status externos. [...] nenhuma experiência de nenhum tipo constitui uma unidade, a menos que tenha qualidade estética. " (DEWEY, 2010, p.117)

Embora Dewey (2010) use o termo estética, que está mais associado a apreciação de uma obra de arte, por exemplo, ele considera que a experiência estética é intrinsecamente ligada à experiência de criar. E que neste sentido a arte desempenha um papel fundamental como potencial geradora de experiências singulares e também significantes. As experiências propostas no LabSensi com a linguagem de dança, por exemplo, não foram propostas como a simples repetição de movimentos em coreografias pré-planejadas, mas foram baseadas em princípios de técnicas somáticas, como body-mind centering ${ }^{\mathrm{TM}} \mathrm{e}$ contato improvisação, relacionadas com algum assunto do modulo temático que cursavam, experiência descrita em encontro de pesquisa em dança e publicada nos anais do encontro (ARAÚJO, 2017).

Os problemas que se seguiram a esta proposta foram de caráter de insuficiência de professores para montar um repertório diverso para os estudantes, e o foco de aulas foi centrado em linguagens de cinema/audiovisual e cinestésica/movimento/dança. Aqui há então uma ampla discussão sobre o que seria optativo e o que deveria ser curricular. Como "obrigar" a aprendizagem do sensível? Ao mesmo tempo, como abrir mão de questões tão fundamentais à formação humana e deixá-las em segundo plano, como se sua importância 
fosse reduzida, como vem sendo ao longo dos anos? Essa discussão, que já havia precedido a primeira mudança do laboratório, emergiu novamente em frequentes reuniões de planejamento pedagógico realizadas entre docentes e com a participação discente, nos anos 2016 e 2017.

Em 2016 um grupo de docentes do curso - que incluía as professoras do laboratório Heloísa Germany e Rafaella Lira, dentre outras docentes que apoiavam o laboratório - fez um longo trabalho que usava como base documentos da matriz de conhecimentos do revalida (BRASIL, 2009) e das diretrizes curriculares (BRASIL, 2014) que sinalizavam as competências, habilidades e atitudes exigidas para a formação médica. Estes documentos foram analisados à luz da Taxonomia de Bloom (FERRAZ e BELHOT, 2010), e foi criado um documento pedagógico que relacionava as competências do documento matriz com as competências do curso e em qual domínio da taxonomia aquela competência estaria alocada. Este documento serviu então de base para os planejamentos pedagógicos das aulas, justificando - como estratégia de sobrevivência - as competências trabalhadas. Vale salientar, que para tantas aulas de conteúdos tidos como "tradicionais" para a medicina, estas competências não eram exigidas de forma clara, e não havia questionamentos dos estudantes quanto a forma como a anatomia ou histologia ou outras áreas das ciências básicas, para citar como exemplo, eram dadas no curso. Assim, para nós estava claro a disputa de poder construída entre os saberes arraigados muito antes do surgimento do curso, paradigma nascido com a racionalidade moderna e sua influência em todas as disciplinas cientificas desde o século XVIII, como explica bem Madel Luz:

\begin{abstract}
A partir do século XVII, e durante a primeira metade do século XVIII, lograr-se-á, com o Mecanicismo, um amálgama de filosofia natural (cosmologia), método experimentalista e sistemas de enunciados e proposições sobre aspectos específicos do objeto natureza. É desse amálgama que se originam as disciplinas cientificas modernas, assinalando uma ruptura epistêmica, mais profunda, de consequências mais significativas para a racionalidade moderna que o próprio Renascimento, na medida em que solidifica a ciência como forma socialmente privilegiada e institucionalmente legitimada de produção de verdades." (LUZ, 1988 , p. 58. Grifos originais).
\end{abstract}

Assim, a discussão entre o optativo e o obrigatório foi retirada do foco quando as competências estavam postas em sala de aula, nos planos pedagógicos relacionados. Todavia, as experiências promovidas pelo laboratório, que muitas vezes traziam uma proposta de deslocamento territorial, no sentido de mover afetos, muitas vezes gerava incômodos. 
Questionamentos sobre aprendizagem significativa eram sempre contextualizados. Todavia, em uma boa parte deles, talvez pelo pragmatismo do fazer médico, pela necessidade de tomar decisões em um caráter mais resolutivo que fizesse sentido imediato à formação em medicina, alguns questionamentos suscitavam apenas um caminho para a resolução de um certo incômodo, e não necessariamente uma reflexão sobre os motivos que levavam à resistência de parte dos alunos. Para Dewey, é possível entender os fatores limitantes das experiências proporcionadas, pois "[...] A resistência é tratada como uma obstrução a ser vencida, e não como um convite a reflexão" (DEWEY, 2010, p.123).

Em 2017, com a colaboração da professora Maria Teresa Lopes Ypiranga, do curso de design e comunicação da UFPE, pudemos refletir sobre o processo de trabalho pedagógico desenvolvido nas aulas do LabSensi - a esta altura estava sendo mais fácil chamar apenas de laboratório de sensibilidades ou LabSensi - a partir do olhar da metodologia de abordagem triangular de Ana Mae Barbosa, conforme cita Lopes em sua experiência em disciplina ofertada ao curso sobre visualidades/formação do olhar (LOPES, 2019). Embora não haja uma perspectiva clara de arte-educação no laboratório, com objetivo de fruição de obras de arte, muitas ideias de Mae coadunam com os aspectos do contemporâneo nas artes com os quais trabalhamos.

Há muitos precedentes na relação entre arte e educação e talvez mais camadas de complexidade ainda na relação com uma medicina que urge pelo pragmatismo, competitividade, pro-ativismo. Ter a noção de arte como campo de conhecimento, dar o espaço para que ela se faça, oportunizar e valorizar experiências sensíveis e inclusive de escuta.... O que os alunos que boicotaram estavam dizendo? Que as camadas sociais que os envolviam e influenciavam não davam espaço para essas experiências... o tempo investido, sem um "propósito" claro, já que "não iriam ser artistas", nem comunistas, nem meditadores, enfim, pareciam demonstrar um reflexo do nosso sistema educacional, carente em formação crítica e experiências artísticas formadoras do humano. Sobre essa disponibilidade "interna" para viver uma experiência, neste caso, estética, Dewey explica o que pode limitar e distorcê-la:

"A experiência é limitada por todas as causas que interferem na percepção das relações entre o estar sujeito e o fazer. Pode haver interferência pelo excesso do fazer ou pelo excesso da receptividade daquilo a que se é submetido. O desequilíbrio em qualquer desses lados embota a percepção das relações e torna a experiência parcial e distorcida, com um significado escasso ou falso. (DEWEY, 2010, p.123) 
O laboratório precisou enfrentar a categoria médica, esta que determina a imagem entre os pares, valoriza ou desvaloriza o lugar do discurso e da verdade para além do discurso científico, já que articula não apenas esse lugar de influência em sua thecné, mas mais por seu caráter político na sociedade.

Uma das experiências vivenciadas de forma integrada entre arte e saúde pública aconteceu com a primeira turma, no módulo Fadiga, Perda de Peso e Anemias" onde a professora coordenadora do módulo articulou a realização de uma mesa de saúde da população negra, e tivemos além de exposições com o perfil epidemiológico desta população, incluindo índices de violência, uma apresentação teatral com atores convidados do movimento negro local, expondo situações de violência, por exemplo, violência obstétrica associada ao racismo contra a mulher negra. Tal foi o nosso choque quando um dos alunos, apesar de todos os dados levantados, questionou: para quê uma política de saúde da população negra? Porque vocês privilegiam os negros ao invés dos brancos? Porque não uma política da população branca? Essa fala nos fez entender que aquele lugar não era de abertura ao aprendizado, mas de simples e superficial contestação, pelo significado da afronta como posicionamento de aversão ao contexto sociopolítico no qual o curso (e a maior parte dos professores tomou esse posicionamento) emergiu de uma macropolítica de esquerda.

A contribuição das recém-chegadas professoras de artes, Heloísa Germany e Rafaella Lira, naquele momento substitutas, foi essencial na construção de um plano pedagógico de "sensibilidades" que dialogasse com os módulos temáticos e a experiência do curso. Com uma formação específica e um modo de estar no mundo singular, pôde-se propor deslocamentos possíveis, em diálogos abertos, a fim de construir experiências acerca do comum, partindo de um lugar fora do espaço de pensamento "medicalizado" ou do olhar biomédico para o corpo, trazendo de volta a perspectiva da vida comum e da vida criativa para a dialética do conhecimento. Mesmo com esse trabalho, havia dificuldades no corpo de docentes como um todo, no sentido tanto de compreender e valorizar o lugar do sensível na construção do conhecimento como também de trazer práticas sensíveis para suas atividades pedagógicas cotidianas, como o trabalho com pequenos grupos. Compreendendo essas diversas dificuldades apresentadas até então, buscamos qualificar os docentes com pequenos cursos distribuídos ao longo do ano e também a troca de experiências entre pares e outras ações que pudessem apoiar e qualificar o trabalho do laboratório. Assim surgiu o projeto "Qualificação e Expansão das Ações do Laboratório de Sensibilidades, Habilidades e Expressão (LABSHEX)" para concorrer ao edital lançado pelo Ministério da Saúde intitulado INOVASUS. O desejo de mover e encontrar pessoas que pensassem de modo parecido ou próximo ao nosso confluiu na inclusão de um encontro nacional sobre o sensível, organizado dentro deste projeto. 


\section{Encontrando alguns pares}

O 1ํ ENSENSI foi uma proposta de atividade dentro de um projeto de extensão mais amplo, intitulado "Qualificação e Expansão das Ações do Laboratório de Sensibilidades, Habilidades e Expressão (LABSHEX)", que foi um projeto do laboratório de sensibilidades do Curso de Medicina de Caruaru (NCV/CAA/UFPE) e era composto de 8 atividades, dentre elas este encontro nacional. Este projeto conquistou o 1ำ lugar da Região Nordeste do Prêmio InovaSUS - Gestão da Educação na Saúde, na Modalidade II (Integração Ensino-Serviço-Comunidade) - Edital 2015, da Secretaria de Gestão do Trabalho e da Educação na Saúde do Ministério da Saúde (SGTES/MS), em parceria com a Organização Pan-Americana da Saúde/Organização Mundial da Saúde (Opas/OMS).

De 27 de fevereiro a 04 de março de 2018, cerca de 118 pessoas participaram do evento, dentre docentes de nível superior de escolas de graduação em saúde e psicologia, discentes e técnicos administrativos, de diversas regiões do país. A programação incluiu oficinas pré-evento, como as oficinas de Clown e Narrativas Existenciais, ofertadas por Ana Nogueira e Fernanda Machaiba, respectivamente, assim como de metodologias sensíveis, como a Sociopoética, facilitada por Jacques Gauthier. Conferências, mesas redondas e GTs estruturaram a programação do evento, que deu voz a discussão sobre a incorporação e às práticas da dimensão do sensível nas graduações e na educação permanente de profissionais de saúde. $O$ evento também promoveu a apresentação e avaliação de trabalhos científicos sobre 0 tema, sendo 29 resumos aceitos, 24 pôsteres apresentados, 06 pôsteres artesanais executados. Este encontro foi um marco para o curso de medicina e para os atores que pensam o processo da transformação da educação médica no país. Apesar de todas as suas dificuldades de organização e realização, muitas pessoas se mobilizaram de diversos lugares para estar presente e ampliar a visão sobre construir as possibilidades de uma formação em saúde (mais) "sensível". Mas o que seria isso?

\section{Os afetos: cartografando pistas do encontro e relatando as paisagens}

Nos dias 02 e 03 de março, a atividade central do ENSENSI foram os Grupos de Trabalho (GT's). Com o título cartografias do sensível, os GT's tinham por objetivo construir espaços de encontro e troca de experiência sobre a incorporação do sensível no ensino, na pesquisa e na extensão dos cursos de saúde. A produção dos grupos foi compartilhada em plenária com os demais participantes do encontro e também com os convidados que foram estimulados 
a contemplar nas suas falas o conteúdo exposto pelos grupos. Essa metodologia permitiu a expressão de ideias, afetos, vivências por parte dos participantes, além de integrar a fala dos convidados com as discussões do grupo. Com essa metodologia do encontro, idealizada por Maria Verônica Oliveira e Rafaela Pacheco, os convidados poderiam não partir de suas verdades "prontas", mas trabalhariam suas falas a partir das demandas emergentes das discussões e poderiam entrar na conversa de forma contextualizada.

Houve quatro GTs com aproximadamente 15 pessoas cada. Os GTs foram facilitados por uma dupla ou trio de professores e estudantes, com diferentes perfis de formação e tempo de experiência profissional. $O$ grupo de facilitadores foi articulado pela organização do evento e passou a trocar ideias, antes mesmo do encontro iniciar.

A divisão dos grupos teve como prerrogativa fazer os participantes se conhecerem e se reconhecerem como parceiros no desafio do ensino do sensível. Para dividir os participantes nos grupos, foi realizado uma metodologia já utilizada no curso de medicina da UFPE/CAA/NCV: o ninho. O ninho consiste em cada facilitador exponha em uma sala objetos pessoais, que contam uma história sobre si, mas que não tragam identificação nominal. Os participantes assim visitam os ninhos e escolhem aquele que mais o afetou, e assim se formam os grupos por afinidade. Essa dinâmica possibilitou a aproximação entre os membros dos grupos por meio de suas subjetividades, o que facilitou 0 processo de diálogo e construção dos grupos.

A tarefa dos facilitadores foi auxiliar nas discussões, sintetizar os principais temas e organizar os grupos para o compartilhamento em plenária. Ademais, um relator participante da comissão organizadora do evento ajudou na relatoria. Esses registros dos GTs constituem parte do material de pesquisa deste artigo.

As discussões nos grupos foram desencadeadas por meio de perguntas norteadoras, com dois focos principais: identificar o lugar que a educação sensível tem ocupado nas graduações e traçar estratégias, possibilidades e identificar limites, além de criar cooperação entre as instituições. Os focos foram sintetizados pela organização do evento e as perguntas orientadoras foram as seguintes:

Tabela 1. Perguntas orientadoras dos Grupos de Trabalho do $1^{\circ}$ ENSENSI.

$1^{\circ}$ dia - As cores e texturas da paisagem: Desenhos Epistêmico- metodológicos.

- O que entendemos como educação do sensível?

- O que fazemos em cada lugar?

- Como fazemos em cada lugar? 
$2^{\circ}$ dia - A esperança equilibrista: estratégias de (re)existência. Potências, limites e necessidades de cada lugar.

- O que podemos fazer em cada lugar?

- O que podemos fazer juntxs?

- O que precisamos fazer?

Fonte: relatórios do evento disponibilizados pelos organizadores.

Diante da riqueza e multiplicidade das falas, gestos e afetos produzidos no encontro, incluindo os GTs, esse artigo pretende materializar aspectos centrais, de modo que não se propõe a abarcar todas as discussões ocorridas nos GT's.

Borboletas me convidaram a elas.

O privilégio insetal de ser uma borboleta me atraiu.

Por certo eu iria ter uma visão diferente dos homens e das coisas.

Eu imaginava que o mundo visto de uma borboleta seria, com certeza, um mundo livre aos poemas.

Daquele ponto de vista:

Vi que as árvores são mais competentes em auroras do que os homens.

Vi que as tardes são mais aproveitadas pelas garças do que pelos homens.

Vi que as águas têm mais qualidade para a paz do que os homens.

Vi que as andorinhas sabem mais das chuvas do que os cientistas.

Poderia narrar muitas coisas ainda que pude ver do ponto de vista de uma borboleta.

Ali até o meu fascínio era azul.

Manoel de Barros, 2000.

A educação sensível ocupa um lugar de ruptura dentro das graduações em saúde, uma vez que ela procura despertar, nos estudantes, formas contra hegemônicas de construção de sentido para o processo de ensinoaprendizagem nessa área. Esse olhar na formação disputa espaços com outras disciplinas consideradas mais importantes ou tradicionalmente legitimadas, segundo o modelo de racionalidades biomédicas. Nesse contexto, ainda há muita resistência entre os estudantes pois a "utilidade" do saber sensível é questionada. Podemos olhar para esse contexto a partir do que traz Thomas Kuhn:

A ciência normal não tem como objetivo trazer à tona novas espécies de fenômeno; na verdade, aqueles que não se ajustam 
aos limites do paradigma frequentemente nem são vistos. Os cientistas também não estão constantemente procurando inventar novas teorias; frequentemente mostram-se intolerantes com aquelas inventadas por outros. [...] (KUHN, 2011, p.44).

Há, similarmente, o desafio de entender as diferentes capacidades, disponibilidades e possibilidades de se aproximar e compreender essa perspectiva do sensível por parte do conjunto de professores, para além daqueles que já atuam com o tema. Isso também se constitui como um processo contínuo de construção.

A discussão também apontou para compreender de que forma as práticas do sensível tem afetado os estudantes na construção de significados e qual seria o papel do docente para contribuir nesse processo. Acompanhar o processo de perto e trabalhar questões profundas de forma gradual foram estratégias compartilhadas para evitar que estudantes se sintam desamparados durante a produção de significados. Outros docentes, por sua vez, colocam que a produção de significado depende das vivências e experiências acumuladas por cada estudante e que o docente além de ofertar as experiências, tem pouco a fazer, a não ser acompanhar o processo.

O caminho que se percorre para conhecimentos e experiências sensíveis é diverso, múltiplo, rizomático. A diversidade das vivências e dos afetos provocados por elas é marcante e há que se ter a cautela de utilizar técnicas e métodos que não tornem 0 ensino engessado. Entre as experiências apresentadas durante os GT's, destacaram-se: leitura de livros, poesias; músicas; cinema; teatro e teatro do oprimido; dança; produção de narrativas informais, pessoais ou autoficcionais; abordagens lúdicas, artísticas e com artesanato; "caixa de afetações", que são perguntas geradoras de reflexão. Os grupos colocam que essas experiências demonstram a amplitude de caminhos para o conhecimento sensível, e exploram possibilidades de reflexão, autocuidado, cuidado dos outros, entendimento da realidade das pessoas, contato com o corpo para além da anatomia.

A colaboração entre professores e estudantes de diferentes locais foi sinalizada como necessária para a construção de um sentimento de unidade com a finalidade de fortalecer a luta por algo novo e contra hegemônico como é o saber sensível. A organização e o sentimento de grupo foram colocados como essencial para a valorização e aprofundamento do debate sobre o saber sensível. Fóruns, publicações e blogs foram citados como ferramentas para troca de experiências, informações e integração, inclusive com outras áreas, como direito, psicologia, engenharia, física.

Bastante mencionada foi a dificuldade de publicar as experiências sensíveis em periódicos tradicionais, já que estas exigem obediência a certas técnicas metodológicas na qual o saber sensível não pode ser transposto na sua 
essência. A necessidade de negociação com a realidade atual foi somada à discussão, entretanto, ponderou-se que a ramificação do saber sensível em diferentes disciplinas (já em si marginalizadas) poderia desperdiçar potenciais e institucionalizar o saber sensível. As experiências demonstraram o potencial para construção e o fortalecimento de uma nova ciência por meio do desenvolvimento de pesquisas e integrando diversas áreas do conhecimento. Mais uma vez, foi reforçada a necessidade de se constituir uma rede para fortalecer essa ciência. Inquietações das autoras nos forçam a trazer as seguintes questões: seria possível, então a produção de novas verdades nessa perspectiva? Analisando as disputas nos diversos discursos de produção de verdades, quais campos de conhecimento já estão postos - ou deveriam se buscar para - o diálogo?

A construção da formação de profissionais de saúde a partir da perspectiva do desenvolvimento de sensibilidades foi debatido tanto por professores como pelos estudantes. A necessidade de colocar em um ambiente formal (a universidade) pensamentos abertos e diversos foi intensamente debatida. Alguns pontos formaram o tônus dos debates: a complexidade das experiência sensíveis, a diversidade de olhares, o respeito às escolhas; a obrigatoriedade do currículo, a alta carga de exigência nos estudantes, a alta carga emocional, as Diretrizes Curriculares Nacionais das Graduações em Medicina; a negação de realizar as atividade, motivações e ressignificações dos estudantes; a avaliação do espaço; a integração entre atividades dentro da universidade e os estágios

O relatório da plenária final do evento demonstra que os caminhos que as discussões trilharam foram na linha da agregação e publicização, em consonância com o discutido nos GTs. Pela agregação, comentou-se da necessidade de encontros presenciais (um segundo ENSENSI), trocas de experiências, sites e outros recursos que podem ser utilizados a distância. A divulgação de atividades, vivências e estudos sobre a educação sensível na área da saúde também arrematou as discussões dos GTs. Mesmo com as dificuldades comentadas, colocou-se também a necessidade de realizar projetos de pesquisa para fomentar o desenvolvimento dessa forma de pensar a formação profissional.

\section{Considerações finais}

Viver é afinar o instrumento

De dentro prá fora

De fora prá dentro

A toda hora, todo momento

(...)

Tudo é uma questão de manter 
A mente quieta

A espinha ereta

E o coração tranquilo

Walter Franco, música Serra do Luar

Do encantado artístico ao fazer criativo, seguimos apostando na arte como caminho possível. Do interesse inicial pela habilidade médica a descobrir na relação entre as pessoas - seja médico-paciente ou cuidador-pessoa - a singularidade do encontro e das potências que ele pode produzir. Da necessidade de receber cuidado a permitir uma oportunidade de tempo para se auto testemunhar, auto perceber e o cuidar de si. É sobre isso que buscamos aprofundar até o momento, por trilhas diversas, ora mais tortuosas, ora sem muita clareza, mas em muitas outras com feedbacks surpreendentes de estudantes que participam das aulas.

As resistências vão sempre existir, a questão que se coloca como central aqui é: como manter-se vivo ou viva? Manter vivo e ativo o humano, valorizar e dar espaço para o sensível na disputa das formações acadêmicas pautadas pela ciência cartesiana ainda arraigada em nosso fazer-pesquisa e ensinoaprendizagem em saúde, como? Estratégias poético-pedagógicas são fundamentais para tornar visível outras construções possíveis para além do hegemônico. É preciso lembrar que são muitas camadas construídas de imagem do que seria o/a profissional médico/a ideal no imaginário dos/as alunos/as, e neste sentido não é possível descontextualizar o ensino no campo de sensibilidades de um contexto macropolítico, especialmente o que manipula a ciência na direção de um desenvolvimento tecnológico e econômico apartado de um desenvolvimento humanístico. Como explica Edgar Morin (2003),

O desenvolvimento ignora que o crescimento tecno-econômico
produz também subdesenvolvimento moral e psíquico: a
hiperespecialização generalizada, as compartimentalizações em
todos os setores, o hiperindividualismo, os espíritos de lucro
provocam a perda da solidariedade. A educação disciplinar do
mundo desenvolvido traz bastante conhecimento, mas engendra
um conhecimento especializado que é incapaz de perceber os
problemas multidimensionais e determina a incapacidade
intelectual de reconhecer os problemas fundamentais e globais.
(MORIN, 2003).

Segundo Morin (2003), é possível manter a esperança na desesperança, já que a própria humanidade carrega em si a capacidade de se regenerar, a partir da ideia das células tronco e do homem genético, citando Marx (MORIN, 2003, p. 20). Nossas esperanças foram alimentadas nas discussões desenvolvidas durante o Ensensi, que trouxeram uma variedade de temas que interferem 
diretamente no cotidiano da educação sensível. Porém, um percalço é essa educação ocupar um lugar contra hegemônico dentro das universidades, e, por vezes, marginal. A garantia de espaços para as subjetividades, a escuta, 0 protagonismo, a autonomia e a flexibilidade para organizar o processo metodológico do ensino do sensível, convergindo para uma ruptura paradigmática do ensino da área da saúde, foi apontada como necessária.

A maior parte das experiências apresentadas no encontro são realizadas em espaços diversos da normativa curricular ainda vigente, estando em sua maioria nas vivências com os usuários em serviço e em projetos de extensão. A curricularização dessas experiências é campo de disputa, com muitos tensionamentos, como vivido pelo LabSensi em Caruaru e descrito neste artigo. Isso indica que, apesar das diretrizes dos cursos da área da saúde e da prática cotidiana do trabalho em saúde solicitar dos estudantes e profissionais um olhar e uma prática mais sensíveis, a estrada nessa direção precisa ser construída. E as práticas compartilhadas no primeiro Ensensi ajudam a dar uma orientação. É importante salientar que eu as discussões levantadas nos grupos abordam um conjunto de temas cujas reflexões precisam ser aprofundadas e que dizem respeito às contradições existentes na formação dos profissionais de saúde.

O ENSENSI pode ser visto como uma trilha aberta que faz com que as reflexões e vivências que vínhamos tecendo no LabSensi extrapolem suas fronteiras indo ao encontro da pluralidade do que vem sendo realizado em outros lugares do país. Que caminhos se abrem para nós agora?

O laboratório de sensibilidades como espaço pedagógico permanece em construção, renovando-se a cada turma e a cada professor, a cada experiência. Desejamos que seja vivo e que persista no tempo, a transformar relações e vidas em conjunto para tolerância, resiliência e humanidade. O evento nacional nos trouxe muitas esperanças, que acreditamos ter sido espalhada para vários docentes e discentes no país. E seguimos agora com a pergunta: por onde vamos continuar trilhando?

\section{REFERÊNCIAS}

ARAÚJO, Eline Gomes de. Contato improvisação e AIDS: dança enquanto podercorpo e saber-poder. Dissertação (mestrado) - Universidade Federal da Bahia, Escola de Dança, Salvador, 2010. $137 \mathrm{f}$.

ARAÚJO, Eline Gomes de. Princípios de MBC e contato improvisação como recurso pedagógico num curso de medicina: relato de experiência. Anais do $\mathrm{V}$ Encontro Científico Nacional de Pesquisadores em Dança. Natal: ANDA, 2017. p. 892899.

BARROS, Manoel de. Ensaios fotográficos. Rio de Janeiro: Record, 2000. 
BRASIL. Ministério da Educação. Conselho Nacional de Educação. Câmara de Educação Superior. Resolução CNE/ CES no116, de 3 de abril de 2014. Institui diretrizes curriculares nacionais do curso de graduação em Medicina. Diário Oficial da União. Brasília, 6 de jun, de 2014; Seção 1, p.17.

BRASIL. Ministério da Educação. Secretaria de Ensino Superior. Ministério da Saúde. Secretaria de Gestão do Trabalho e Educação na Saúde. Matriz de correspondência curricular para fins de revalidação de diplomas de médico obtidos no exterior. Brasília, MEC, MS, 2009. 69p.

DAMÁSIO, Antônio. O mistério da consciência. São Paulo: Companhia das Letras, 2000.

DEWEY, John. Arte como experiência. Tradução Vera Ribeiro. São Paulo: Martins Fontes, 2010.

DUARTE JÚNIOR, J. F. O sentido dos sentidos: a educação (do) sensível. 2000. Tese (Doutorado em Educação) - Faculdade de Educação, Universidade Estadual de Campinas, Campinas, 2000.

FERRAZ, Ana Paula do Carmo M., BELHOT, Renato Vairo. Taxonomia de Bloom: revisão teórica e apresentação das adequações do instrumento para definição de objetivos instrucionais. Rev. Gestão \& Produção. São Carlos, v. 17, n. 2, p. 421 431,2010

FOUCALT, Michel. História da sexualidade 3. O cuidado de si. Rio de Janeiro: Edições Graal, 1985.

GERMANY, Heloísa. Laboratório de Sensibilidades: Arte na Formação Médica. Anais do 55 COBEM - Congresso Brasileiro de Educação Médica. Pôster. Porto Alegre: Associação Brasileira de Educação Médica, 2017.

GREINER, Christine. O corpo. Pistas para estudos indisciplinares. São Paulo: Annablume, 2005.

HOUAISS. Dicionário eletrônico da língua portuguesa, Editora Objetiva, versão 3.0. KATZ, Helena. Um, dois, três. A dança é o pensamento do corpo. 1 ed. Belo Horizonte: Helena Katz, 2005.

KUHN, Thomas. A estrutura das revoluções científicas. 11르 ed. São Paulo: Perspectiva, 2011.

LOPES, Maria Teresa. Uma proposta da moda como conhecimento para formação do olhar do estudante de medicina no agreste pernambucano. Ensinarmode, Vol. 3, n. 1, p.047 - 058, 2019. ISSN 2594-4630.

LUZ, Madel T. Natural, Racional, Social. Razão médica e racionalidade científica moderna. 3를 ed. São Paulo: Hucitec, 2012.

MERHY, E. E. Um ensaio sobre o médico e suas valises tecnológicas. Interface comunicação, saúde, educação, vol.6, pp. 109-25, fev. 2000. 
MERHY, E. E. Dicionário da educação profissional em saúde. Fundação Oswaldo Cruz. Escola Politécnica Joaquim Venâncio, 2009.

MERHY, E. E. Vivenciar um campo de formação de profissionais de saúde: dobrando em mim o fazer da Unifesp-Baixada Santista. In: CAPOZZOLO, Angela A., CASETTO, Sidnei J., HENZ, Alexandre O. (Org). Clinica comum: itinerários de uma formação em saúde. São Paulo: Hucitec, 2013.

MORIN, Edgar. Para Além da Globalização e do Desenvolvimento: sociedade mundo ou império mundo? In: CARVALHO, E.A.; MENDONÇA, T. Ensaios de Complexidade 2. Porto Alegre: Sulina, 2003. 312 p.

MUKUNDA, Neha e cols. Visual art instruction in medical education: a narrative review. Medical Education Online. Vol.24, n.1, 2019. DOI: 10.1080/10872981.2018.1558657

OLIVEIRA, Maria Verônica Araújo de Santa Cruz. A educação em saúde para além das palavras, um encontro com o sentir. In: RODRIGUES, L. D.; VASCONCELOS, E. M. (Org.). Novas configurações em movimentos sociais, vozes do Nordeste. João Pessoa: Ed. Universitária, 2000. p. 95-115.

ONO, Yoko. Acorn. Tradução Carolina Caires Coelho. $1^{\text {a }}$ ed. São Paulo: Editora Bateia, 2014

PESCUMA, Cristina. Pensamento da diferença: potência e acontecimento. In: PASQUALI, Lanussi. A arte contemporânea e o pensamento da diferença. Bahia, 2013. ISBN 978-85-67099-01-9

VASCONCELOS, Eymard Mourão. Educação popular e a atenção à saúde da família. $2^{\underline{a}}$ ed. São Paulo: Hucitec, Sobral: Uva, 2001.

VIEIRA, Jorge de Albuquerque. Teoria do conhecimento e arte. Formas de conhecimento: arte e ciência, uma visão a partir da complexidade. Fortaleza: Expressão Gráfica e Editora, 2006.

UFPE-Universidade Federal de Pernambuco, Centro Acadêmico do Agreste, Núcleo de Ciências da Vida, Curso de Medicina. Projeto Pedagógico do Curso de Medicina. Caruaru, 2014. Mimeo. 